10.1590/S1414-40772018000200016

Este é um artigo publicado em acesso aberto sob uma licença Creative Commons https://creativecommons.org/licenses/by-nc/4.0/

\title{
A produção científica sobre docência no ensino superior: uma análise bibliométrica da SciELO Brasil
}

\author{
Paulo Roberto Cintra ${ }^{1}$
}

Resumo: A maioria das políticas públicas brasileiras sempre tiveram como foco a pesquisa científica, dando pouca importância às práticas pedagógicas. Por esse motivo, o objetivo deste artigo é analisar a produção científica acerca da docência no Ensino Superior. Para tanto, foram construídos indicadores bibliométricos, elaborados a partir de uma coleta de dados na base da SciELO Brasil. Os resultados apontaram para uma tendência ascendente no número de publicações versando sobre o assunto analisado. As principais temáticas dessa produção foram a respeito das práticas didáticas, sistemas de avaliação e saúde do docente. Verificou-se que alguns dos periódicos que mais publicaram artigos sobre o assunto não são da área da Educação, mas de outros campos científicos como Química, Medicina e Enfermagem. Conclui-se que a crescente importância da discussão dentro da comunidade científica demonstra que as políticas públicas deveriam se adequar às necessidades do Ensino Superior, de modo que a formação didática do futuro professor também seja uma prioridade.

Palavras-chave: Docência. Ensino superior. Indicadores bibliométricos. SciELO.

\section{The scientific production on teaching in higher education: a bibliometrics analysis of SciELO Brazil}

Abstract: Most Brazilian public policies have always focused on scientific research, giving little importance to pedagogical practices. For this reason, the aim of this article is to analyze the scientific production about teaching in Higher Education. For this purpose, bibliometrics indicators were constructed, based on a data collection from the SciELO Brazil. The results pointed to an upward trend in the number of publications about the subject analyzed. The main themes of this production were related to didactic practices, evaluation systems and teacher's health. It was verified that some of the journals that have more published articles on the subject are not from the area of Education, but of other scientific fields like Chemistry, Medicine and Nursing. It is concluded that the growing importance of the discussion within the scientific community demonstrates that public policies should be adapted to the needs of higher education, so the didactic training of the future teacher should also be a priority.

Key words: Teaching. Higher education. Bibliometrics indicators. SciELO. 


\section{Introdução}

Conforme aponta Gil (2010), por muito tempo pensou-se que o docente do Ensino Superior precisava apenas ter conhecimentos sólidos sobre a disciplina lecionada e uma comunicação clara para expor essas informações. O autor explica que essa situação justificava-se pelo fato do corpo discente ser formado prioritariamente por adultos. Ou seja, diferentemente do ensino básico, no qual a grande maioria dos alunos são crianças e adolescentes, os discentes da graduação e pós-graduação, teoricamente, já sabem quais são suas aspirações futuras, haja vista que possuem personalidade própria. Nesse sentido, a única preocupação do Estado era a de que o professor tivesse uma sólida formação de pesquisador, pois, em tese, "quanto melhor pesquisador fosse mais competente professor seria" (p. 1).

Moreira e Velho (2008) corroboram para essa afirmação ao mostrarem a existência de movimentos governamentais ocorridos nos países centrais no pós-Segunda Guerra Mundial, em especial no que diz respeito à formação de recursos humanos qualificados. Surgidas prioritariamente nos Estados Unidos, as primeiras políticas públicas nesse sentido buscaram delinear o papel da ciência dentro da sociedade. Nesse sentido, destaca-se o relatório Science, the Endless Frontier, de Vannevar Bush, com conteúdo predominantemente positivista, que, dentre outras atribuições, descrevia o papel do governo de criar, viabilizar e fortalecer o ambiente necessário à ampliação do capital científico, através da formação de mestres e doutores. Tais recomendações tiveram impactos no Brasil, em especial, na coordenação do Sistema Nacional de Pós-Graduação que, dado sua atuação junto às universidades, providenciou o impulso essencial ao desenvolvimento dos sistemas de inovação científica e tecnológica. Nesse sentido, a partir da década de 1950, observou-se também a criação de diversas instituições a fim de corroborar para execução da pesquisa no país, entre os quais podemos citar o CNPq (na época, Conselho Nacional de Pesquisas), o ITA (Instituto Tecnológico de Aeronáutica) e a UnB (Universidade de Brasília).

Infere-se por esse contexto que as políticas públicas brasileiras sempre estiveram focadas no sentido de melhorar as pesquisas científicas no país, ao invés de incentivar o aprimoramento das práticas didáticas em professores dos cursos de graduação e pósgraduação. Conforme aponta Ponce e Oliveira (2011), a fim de atuar como professor, além de ter conhecimentos das teorias de sua área de conhecimento, é requerido que esse profissional detenha saberes a respeito da prática pedagógica, de maneira que possa contribuir para formação dos novos estudantes. Gil (2010) concorda com esta visão, pois, para exercer em 
sua plenitude a função de docente do Ensino Superior, é necessário que o professor possua habilidades didáticas compatíveis com sua atividade. Ademais, para o autor, é fundamental que o docente apresente uma ampla percepção a respeito da educação, da ciência, do mundo e do que é ser humano.

Gil (2010) reconhece também que o modelo tradicional de ensino ainda é utilizado por muitos professores universitários, que aprenderam a ministrar aulas sem uma preparação pedagógica particular. Segundo o autor, esses docentes universitários mantém uma atitude conservadora, pois consideram que a transmissão dos conhecimentos, através de aulas expositivas, é a principal forma de ensino. Cabe ressaltar, contudo, que nem todos os professores são adeptos da abordagem tradicional, haja vista que acreditam que o ensino deveria ir além da simples transferência de conteúdo. Nesses casos, o aluno torna-se sujeito ativo da aprendizagem, que constrói seu conhecimento através do entrelaçamento das informações que lhe são transmitidas com aquelas que obtém através de pesquisa. $O$ professor, portanto, "mais do que transmissor de conhecimento, é um facilitador da aprendizagem" (GIL, 2010, p. 9).

De acordo com Soares e Cunha (2010) os estudos acerca da formação do docente do Ensino Superior, no cenário internacional, começam a se intensificar somente a partir da década de 1980, período em que se passa a discutir o papel da educação superior e do professor universitário. Furlanetto (2003), porém, ressalta que a maioria das pesquisas relacionadas à aprendizagem são voltadas para a investigação do ensino nas etapas da infância e adolescência. Para o autor, são poucos pesquisadores que trabalham com a temática acerca do ensino para adultos. Para Hayashi (2004), identificar a produção científica sobre o assunto, dentro do campo da educação, é importante para que seja ampliado a acesso à informação aos profissionais que atuam nessa área. Ademais, o autor afirma que estudos deste tipo podem oferecer subsídio para orientação de pesquisas futuras.

Embora existam estudos que analisem a produção científica a respeito de assuntos referentes à área da educação (HAYASHI, 2004; SILVA, 2008; PIZZANI, 2009; SACARDO, 2012), de fato são poucos os que abordam sobre a docência e, em ainda menor número, aqueles que levantam informações acerca da docência do Ensino Superior. Por esse motivo, o objetivo desta pesquisa é investigar e analisar a produção científica sobre a docência no Ensino Superior na base de dados da plataforma SciELO Brasil, através da elaboração de indicadores bibliométricos. Para tanto, o trabalho foi estruturado da seguinte maneira: nesta primeira seção foram apresentados a importância do tema e o objetivo proposto para a pesquisa. Na segunda seção é realizada uma breve caracterização sobre a educação no Ensino 
Superior, com foco na participação do docente universitário no processo de ensinoaprendizagem. A terceira seção explicita os procedimentos que foram empregados para o desenvolvimento do estudo e a quarta traz os resultados alcançados acerca da produção científica em docência do Ensino Superior, com apresentação dos indicadores bibliométricos elaborados. Por fim, na quinta seção são apresentadas as considerações finais.

\section{0 papel do docente na educação do ensino superior}

A Educação Superior no Brasil é caracterizada pela Lei 9.394/96 - a Lei de Diretrizes e Bases da Educação Nacional (LDB) - em seu artigo 43, como a responsável por:

I - estimular a criação cultural e o desenvolvimento do espírito científico e do pensamento reflexivo;

II - formar diplomados nas diferentes áreas de conhecimento, aptos para a inserção em setores profissionais e para a participação no desenvolvimento da sociedade brasileira, e colaborar na sua formação contínua;

III - incentivar o trabalho de pesquisa e investigação científica, visando o desenvolvimento da ciência e da tecnologia e da criação e difusão da cultura, e, desse modo, desenvolver o entendimento do homem e do meio em que vive;

IV - promover a divulgação de conhecimentos culturais, científicos e técnicos que constituem patrimônio da humanidade e comunicar o saber através do ensino, de publicações ou de outras formas de comunicação;

$\mathrm{V}$ - suscitar o desejo permanente de aperfeiçoamento cultural e profissional e possibilitar a correspondente concretização, integrando os conhecimentos que vão sendo adquiridos numa estrutura intelectual sistematizadora do conhecimento de cada geração;

VI - estimular o conhecimento dos problemas do mundo presente, em particular os nacionais e regionais, prestar serviços especializados à comunidade e estabelecer com esta uma relação de reciprocidade;

VII - promover a extensão, aberta à participação da população, visando à difusão das conquistas e benefícios resultantes da criação cultural e da pesquisa científica e tecnológica geradas na instituição.

VIII - atuar em favor da universalização e do aprimoramento da educação básica, mediante a formação e a capacitação de profissionais, a realização de pesquisas pedagógicas e o desenvolvimento de atividades de extensão que aproximem os dois níveis escolares (BRASIL, 1996).

Nesse sentido, ao observar as características específicas do Ensino Superior, verificase que o papel do docente universitário deve ir além de simplesmente transmitir os conteúdos teóricos de sua competência. Conforme Gil (2010), o professor que ministra aulas na Educação Superior passa a ser o profissional mediador do processo de aprendizagem, podendo assumir diferentes funções enquanto ocupa essa posição, como agente de socialização, avaliador, conselheiro, educador, mentor, pesquisador, planejador de aulas, entre outros. Rowe, Bastos e Pinho (2013) acrescentam ainda que a categoria ocupacional do professor universitário pode ser estudada sob diferentes ângulos, pois trata-se de um grupo com características impares. Dessa maneira, os autores apontam que as pesquisas podem ser focadas nas condições de trabalho do docente do Ensino Superior, nos tipos de instituições em 
que este profissional pode atuar, na sua própria laboração como educador, nos diferentes regimes e jornadas de trabalho com que se depara, nas suas relações com os alunos, com a pesquisa, com as diferentes tecnologias que surgem a todo instante e com a sociedade de modo geral. Além disso, podem ser investigados também as formas de ingresso na carreira, a sua formação como docente, os modos de avaliação para o progresso profissional e a necessidade deste em cumprir com os compromissos assumidos, que estão ligados às atividades de docência e pesquisa. Ou seja, é um tema que "caracteriza-se pela diversidade, pela pluralidade de opções, caminhos, alternativas e interesses" (ROWE; BASTOS; PINHO, 2013, p. 503).

Não obstante, Gil (2010, p. 12) acredita também ser necessário às pesquisas sobre a educação do Ensino Superior trazer o conceito da Andragogia, que refere-se "à arte e à ciência de orientar os adultos a aprender". Embora não seja consenso na literatura, para o autor, conduzir a discussão para o contexto andragógico é importante, uma vez que os estudantes do Ensino Superior possuem interesses, necessidades e características que os diferem dos alunos do ensino básico. Entre essas particularidades, Gil (2010) explica, por exemplo, que os adultos tem maior consciência da necessidade de conhecimento, já que suas motivações para aprender se fundamentam na expectativa de melhores empregos e salários, além da própria vontade de crescimento pessoal, autoestima e autoconfiança. Outrossim, existe o fato dos adultos já trazerem alguma experiência ao processo educativo, o que contribui para que o discente também seja responsável pela sua aprendizagem e para o estabelecimento e delimitação do percurso educacional que balizará a sua formação profissional.

Por outro lado, Gil (2010) indica alguns desafios que o professor universitário enfrenta em sua carreira como docente, dentre os quais: dispor de conhecimentos técnicos, ter visão de futuro, ser o mediador do processo e ser capaz de organizar e dirigir situações de aprendizagem, ser capaz de gerar sua própria formação contínua, ser um docente transformador e aberto ao que se passa na sociedade, ser multicultural, intercultural e reflexivo. Além disso, o professor deve ser capaz de trabalhar em equipe, enfrentar os deveres e dilemas éticos da profissão e ser capaz de utilizar as novas tecnologias de informação e comunicação.

Verifica-se, portanto, que o docente do Ensino Superior pode adotar diferentes comportamentos ao ministrar uma aula e assumir diversas funções enquanto um profissional que objetiva elevar os conhecimentos de seus alunos. Não obstante, para Ferenc e Mizukami (2005), a formação do professor universitário ainda é um campo com muitas lacunas, tanto no que diz respeito às práticas docentes, quanto em termos de pesquisa sobre o assunto. Nesse 
sentido, para Vanti (2002), os indicadores bibliométricos podem ser utilizados para que sejam identificadas as potencialidades de temáticas de pesquisa, de instituições, grupos de pesquisa e cientistas que trabalham com determinado assunto. Assim, quando analisados em conjunto, os indicadores oferecem subsídios aos tomadores de decisão para formulação de políticas públicas que contribuam para redução de déficits observados na formação dos profissionais da educação.

\section{Método}

Para esta pesquisa, optou-se pela utilização da SciELO Brasil (Scientific Electronic Library Online), haja vista que esta plataforma agrega um grande conjunto de periódicos brasileiros em um único sistema. Além disso, a escolha foi motivada também pelo fato da SciELO Brasil estar associada à base bibliográfica Web of Science, da empresa Clarivate Analytics, que permite que sejam extraídos todos os metadados dos artigos nela indexados. Conforme explicam Mugnaini, Digiampietri e Mena-Chalco (2014), o vínculo da SciELO com a Web of Science surgiu em 2014, através da criação SciELO Citation Index. Para os autores este vinculo foi importante para que os autores de origem ibero-americanos tivessem ganhos de visibilidade junto à comunidade internacional.

A coleta dos metadados dos artigos foi realizada no dia 16 de julho de 2017, na qual foram selecionados apenas o tipo de documento Artigos e estabeleceu-se um recorte temporal desde o início da série até o ano de 2016. A expressão de busca para a coleta de dados foi realizada no campo Tópico (rótulo TS), que recupera publicações em que os termos pesquisados constem no título, resumo ou palavras-chave. Além disso, a expressão final foi definida a posteriori, isto é, partiu-se de uma expressão-piloto, na qual foi explicitada o tema central da pesquisa e, em seguida, foram utilizadas variações e sinônimos dos termos buscados, conforme observado na literatura. As expressões utilizadas são mostradas na Figura 1. 
Figura 1 - Histórico das expressões de busca realizadas no SciELO Citation Index, da Web of Science

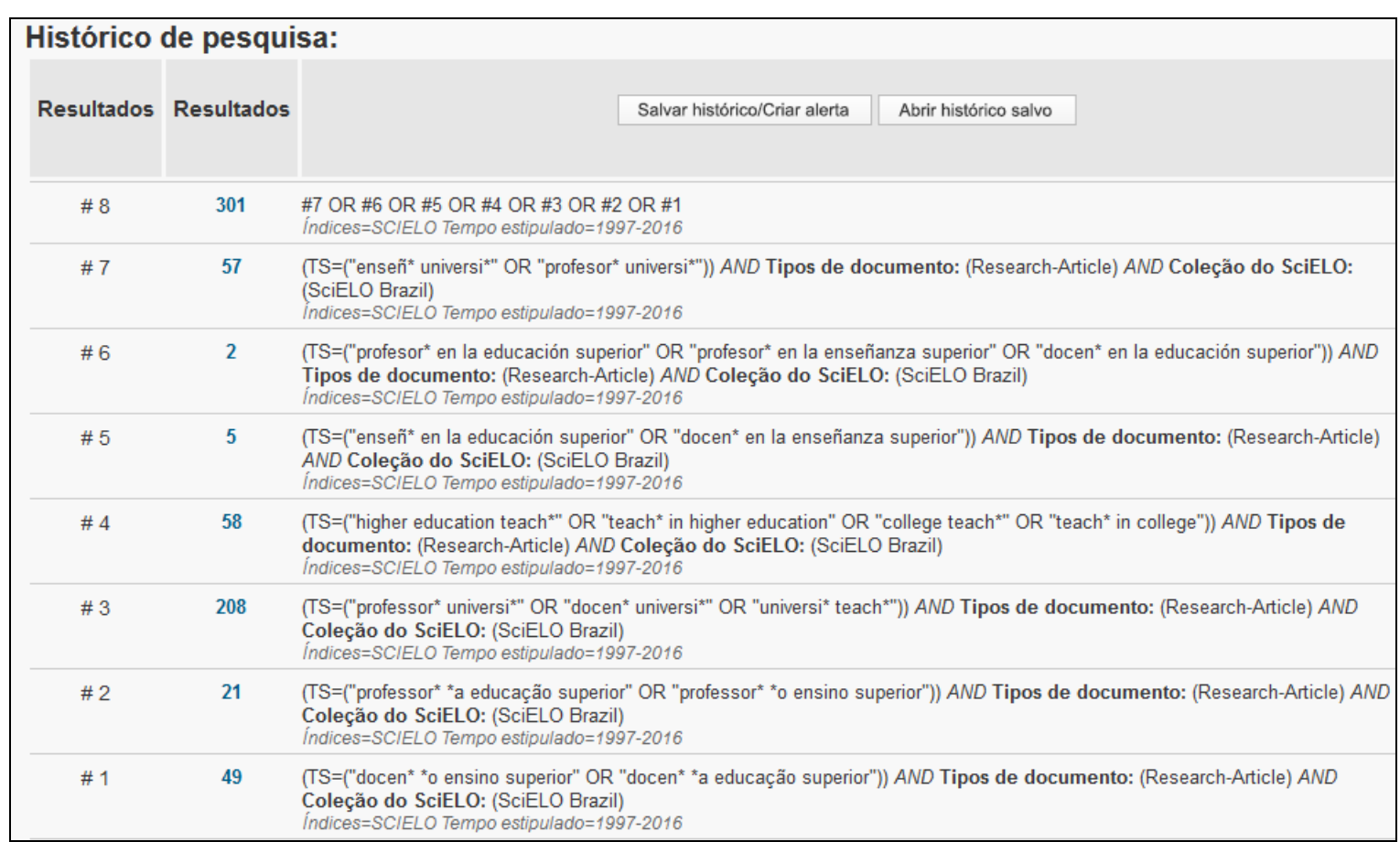

Fonte: SciELO Citation Index

Como é possível observar, a expressão-inicial foi ("docen* *o ensino superior” OR “docen**a educação superior"). O objetivo desta busca e do uso dos asteriscos foi recuperar publicações que abordassem sobre a docência no (ou do) Ensino Superior, ou ainda, que discutissem sobre os docentes da Educação Superior. Nesse sentido, a partir desta primeira expressão de busca realizou-se as variações (docência | teaching | enseñanza), (docente | professor | teacher | profesor), (ensino | educação | education | educación) e (superior | universitário | higher | college). Dessa forma, espera-se cobrir a maioria dos trabalhos que versam a respeito da docência do Ensino Superior dentro da base SciELO Brasil. Salienta-se que a busca por termos em inglês justifica-se pelo fato da maioria das editoras exigir que os autores submetam trabalhos com títulos e resumos na língua inglesa, ainda que o idioma principal do artigo seja português ou espanhol.

A partir das sete primeiras buscas, com os possíveis termos utilizados pelos autores, uma última consulta foi realizada (\#8), na qual somaram-se todos os resultados anteriores. Destaca-se que essa combinação foi efetuada através da utilização do operador booleano (OR), impedindo a existência de documentos duplicados. Uma vez finalizada a pesquisa, os registros de todos os resultados recuperados foram salvos em arquivos de texto, no formato .txt, nos quais eram gravados o Registro completo e as Referências citadas. Esses arquivos de 
texto, por sua vez, foram importados ao programa VantagePoint (versão 5.0), software especializado para compilação de metadados e análise bibliométrica.

Para elaboração dos indicadores de produção científica, após a limpeza e ajustes na padronização dos dados, como correções de inconsistências nos títulos dos artigos e nos nomes dos autores e das instituições de origem desses pesquisadores, as informações organizadas com auxílio do VantagePoint foram exportadas ao software Excel (versão 2013) para construção dos gráficos e tabelas. Entre os indicadores criados, optou-se pelo uso dos referentes aos artigos, aos autores, às instituições e aos países, como índice de produtividade, de atividade e de frequência anual de publicação.

\section{Resultados e discussão}

A partir das buscas realizadas, foram recuperados um total de 301 resultados, sendo que as primeiras publicações remetem ao ano de 2002, conforme mostra o Gráfico 1.

\section{Gráfico 1 - Evolução da quantidade de publicações sobre docência do Ensino Superior na}

\section{SciELO}

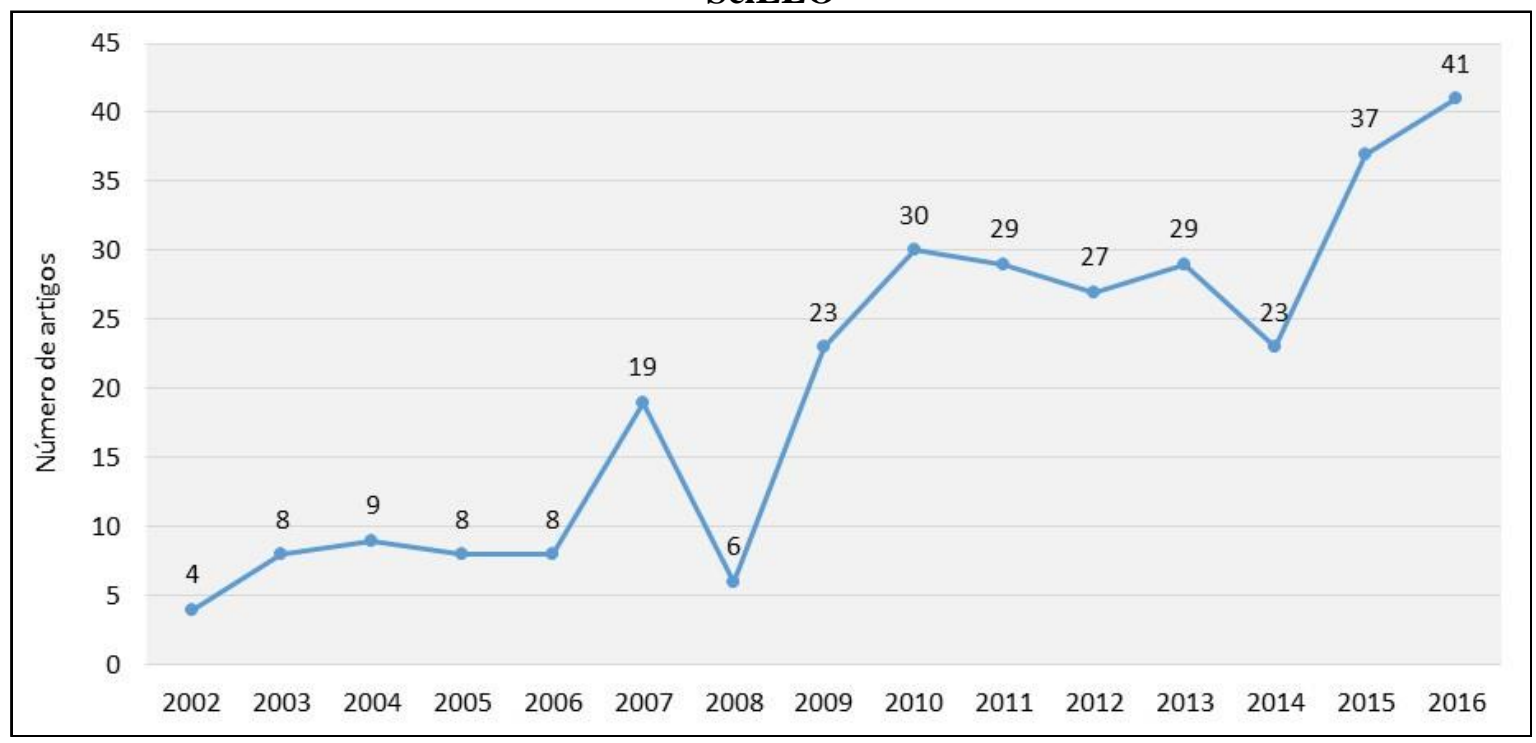

Fonte: Elaboração própria, a partir de dados coletados do SciELO Citation Index

Verifica-se pelo Gráfico 1 que há uma tendência ascendente no número de publicações que abordam sobre a docência no Ensino Superior, com crescimento médio de $38 \%$ ao ano, o que mostra a importância e interesse gradativo pela discussão acerca do tema analisado dentro da comunidade acadêmica.

De modo similar à metodologia utilizada por Urbizagastegui (2008), a Tabela 1 mostra a frequência de distribuição da produção científica sobre docência no Ensino Superior, 
considerando a "contagem completa, quando se credita a produtividade a todos os autores, independentemente de se eles participaram da produção do trabalho como principais ou colaboradores" (URBIZAGASTEGUI, 2008, p. 95, grifo do autor).

Tabela 1 - Frequência de distribuição da produção científica sobre docência no Ensino Superior

\begin{tabular}{ccccc}
\hline $\begin{array}{c}\mathbf{N}^{\mathbf{0}} \text { contribuições } \\
\text { por autor }\end{array}$ & $\mathbf{N}^{\mathbf{0}}$ de autores & \% de autores & $\mathbf{N}^{\mathbf{0}}$ artigos & \% de artigos \\
\hline $\mathbf{1}$ & 680 & $91,9 \%$ & 271 & $73,4 \%$ \\
$\mathbf{2}$ & 44 & $5,9 \%$ & 52 & $14,1 \%$ \\
$\mathbf{3}$ & 13 & $1,8 \%$ & 32 & $8,7 \%$ \\
$\mathbf{4}$ & 1 & $0,1 \%$ & 4 & $1,1 \%$ \\
$\mathbf{5}$ & 2 & $0,3 \%$ & 10 & $2,7 \%$ \\
\hline Total & $\mathbf{7 4 0}$ & $\mathbf{1 0 0} \%$ & $\mathbf{3 6 9}$ & $\mathbf{1 0 0} \%$ \\
\hline
\end{tabular}

Fonte: Elaboração própria, a partir de dados coletados do SciELO Citation Index

Verifica-se que o número total de número de artigos da Tabela 1 (369) é superior ao total de publicações do conjunto de dados da pesquisa (301). Isso ocorre justamente pelo fato de um mesmo artigo poder ter contribuições de diferentes pesquisadores. Com efeito, do total de artigos, 75,3\% foram escritos em co-autoria entre dois ou mais autores, sendo que os demais $(24,7 \%)$ são resultado do trabalho de um único pesquisador. Outrossim, a partir da Tabela 1, percebe-se que são poucos autores que escrevem com frequência sobre a docência no Ensino Superior, sendo que a maioria deles apenas o faz uma vez. Mesmo as pesquisadoras com maior número de artigos, Ana Luiza de Quadros e Maria Isabel da Cunha, possuem apenas cinco publicações cada. Não obstante, tal resultado é relativamente próximo ao proposto pela Lei do Elitismo, de Derek de Solla Price, que estabelece "que 1/3 da literatura é produzida por menos de $1 / 10$ dos autores mais produtivos \&\#091;...\&\#093; e 60\% dos autores produzindo um único documento" (ARAÚJO, 2006, p. 14).

A Tabela 2 apresenta o ranking dos países de origem das instituições onde atuam os autores que tiveram participação em ao menos uma publicação, com o apontamento do número total de artigos em seus valores absolutos e a frequência percentual de cada nação em relação ao total de registros encontrados. 
Tabela 2 - Países de origem das instituições onde atuam os autores da amostra

\begin{tabular}{|c|c|c|c|}
\hline Ranking & Países & Registros & Frequência \\
\hline$\# 1$ & Brasil & 243 & $76,6 \%$ \\
\hline$\# 2$ & Espanha & 19 & $6,0 \%$ \\
\hline$\# 3$ & Argentina & 10 & $3,1 \%$ \\
\hline$\# 4$ & Estados Unidos & 8 & $2,5 \%$ \\
\hline$\# 5$ & Portugal & 8 & $2,5 \%$ \\
\hline \#6 & Chile & 7 & $2,2 \%$ \\
\hline$\# 7$ & Canadá & 4 & $1,3 \%$ \\
\hline$\# 8$ & Colômbia & 4 & $1,3 \%$ \\
\hline \#9 & Nigéria & 3 & $0,9 \%$ \\
\hline$\# 10$ & França & 2 & $0,6 \%$ \\
\hline$\# 11$ & Austrália & 1 & $0,3 \%$ \\
\hline$\# 12$ & Cuba & 1 & $0,3 \%$ \\
\hline$\# 13$ & Irlanda do Norte & 1 & $0,3 \%$ \\
\hline$\# 14$ & México & 1 & $0,3 \%$ \\
\hline$\# 15$ & Nepal & 1 & $0,3 \%$ \\
\hline$\# 16$ & Panamá & 1 & $0,3 \%$ \\
\hline$\# 17$ & Peru & 1 & $0,3 \%$ \\
\hline$\# 18$ & Reino Unido & 1 & $0,3 \%$ \\
\hline$\# 19$ & Uruguai & 1 & $0,3 \%$ \\
\hline$\# 20$ & Venezuela & 1 & $0,3 \%$ \\
\hline
\end{tabular}

Fonte: Elaboração própria, a partir de dados coletados do SciELO Citation Index

Como é possível observar, dos 20 países presentes na Tabela 2, o Brasil lidera o ranking com 243 registros, respondendo por mais de 3/4 de todas as publicações sobre o tema em análise. Isso demonstra o quão doméstica é a produção científica divulgada através dos periódicos pertencentes ao SciELO Brasil. A fim de melhor ilustrar a distribuição geográfica dos países de origem das instituições onde atuam os autores, elaborou-se a Figura 2. 
Figura 2 - Distribuição geográfica dos países de origem das instituições onde atuam os autores

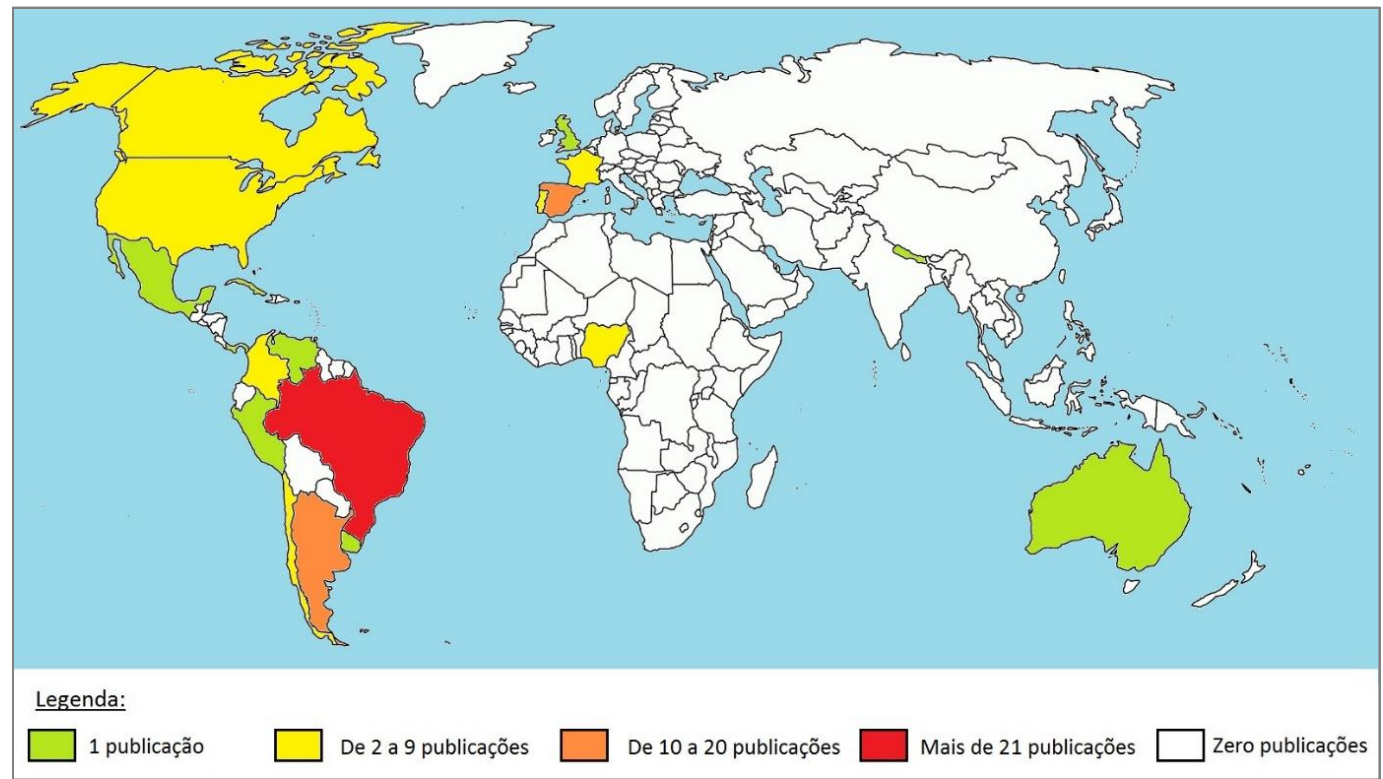

Fonte: SciELO Citation Index

Observa-se da Figura 2 que regiões que poderiam ter contribuições relevantes para a área, como Europa Oriental, África e de pesquisadores advindos do continente asiático, possuem poucas publicações. Tal situação corrobora para o entendimento de Packer e Meneghini (2014) de que o público-alvo da maioria das revistas científicas latino-americanas são as comunidades regionais de pesquisadores, o que faz com que os estudos por eles realizados também se caracterizem por um interesse local. Outro fator que contribui para a baixa internacionalização da produção científica na SciELO Brasil diz respeito ao idioma utilizado nas publicações dos periódicos vinculados à plataforma. Dos 301 artigos da amostra, 231 foram escritos na língua portuguesa (76,7\%), ao passo que 37 estão em inglês $(12,3 \%)$ e 33 em espanhol $(11,0 \%)$.

A Tabela 3 apresenta as principais universidades onde atuam os pesquisadores que escreveram sobre docência do Ensino Superior. Este é um indicador importante, já que mostra quais instituições tem maior representatividade quando se disserta sobre o assunto. 
Tabela 2 - Instituições onde atuam os pesquisadores que publicaram sobre docência do Ensino Superior

\begin{tabular}{|c|c|c|c|}
\hline Ranking & Instituições & Sigla & Registros \\
\hline$\# 1$ & Universidade de São Paulo & USP & 42 \\
\hline \#2 & Universidade Estadual Paulista "Júlio de Mesquita Filho" & UNESP & 21 \\
\hline \#3 & Universidade Estadual de Londrina & UEL & 13 \\
\hline \#4 & Universidade Estadual de Campinas & Unicamp & 12 \\
\hline \#5 & Universidade Federal da Bahia & UFBA & 12 \\
\hline \#6 & Universidade Federal do Rio de Janeiro & UFRJ & 10 \\
\hline$\# 7$ & Universidade Federal de Santa Catarina & UFSC & 10 \\
\hline \#8 & Universidade Federal de Viçosa & UFV & 10 \\
\hline \#9 & Universidade de Brasília & UnB & 9 \\
\hline$\# 10$ & Universidade Federal de São Paulo & UNIFESP & 9 \\
\hline$\# 11$ & Universidade Federal do Rio Grande do Sul & UFRGS & 9 \\
\hline$\# 12$ & Pontifícia Universidade Católica do Rio de Janeiro & PUC-Rio & 7 \\
\hline \#13 & Universidade Católica de Brasília & UCB & 7 \\
\hline$\# 14$ & Universidade Federal de Mato Grosso do Sul & UFMS & 7 \\
\hline$\# 15$ & Universidade Federal de Lavras & UFLA & 6 \\
\hline$\# 16$ & Universidade do Vale do Rio dos Sinos & Unisinos & 6 \\
\hline$\# 17$ & Universidade Federal de Goiás & UFG & 5 \\
\hline$\# 18$ & Universidade Federal de Minas Gerais & UFMG & 5 \\
\hline$\# 19$ & Universidade Federal de Pelotas & UFPEL & 5 \\
\hline \multirow[t]{4}{*}{$\# 20$} & Universidade Tecnológica Federal do Paraná & UTFPR & 5 \\
\hline & Instituições com participação em 2 a 4 artigos & - & 48 IES \\
\hline & Instituições com participação em 1 artigo & - & 133 IES \\
\hline & Total & - & 201 IES \\
\hline
\end{tabular}

Fonte: Elaboração própria, a partir de dados coletados do SciELO Citation Index

Nota 1: Registros refere-se ao número de artigos publicados.

Nota 2: IES é o acrônimo para Instituições de Ensino Superior.

Verifica-se que as 20 primeiras instituições do ranking são universidades brasileiras, ou seja, há uma baixa participação na literatura sobre docência no Ensino Superior de pesquisadores ligados a universidades estrangeiras ou mesmo a outros institutos de pesquisa. Ademais, destaca-se que a Universidade de São Paulo (USP) lidera o ranking das instituições cujos pesquisadores realizaram trabalhos acerca da temática investigada, com um total de 42 artigos publicados. Em seguida, aparecem outras duas universidades estaduais: Universidade Estadual Paulista "Júlio de Mesquita Filho" (UNESP - 21 publicações) e Universidade Estadual de Londrina (UEL - 13 publicações). Observa-se ainda que a maioria das instituições líderes na publicação científica sobre docência são públicas, estejam elas vinculadas ao governo federal ou estadual. Não obstante, as universidades particulares se fazem presente neste ranking através da Pontifícia Universidade Católica do Rio de Janeiro (PUC-Rio), da Universidade Católica de Brasília (UCB) e da Universidade do Vale do Rio dos Sinos 
(Unisinos). É importante salientar que grande parte dos pesquisadores de instituições particulares, em sua maioria, aparecem agregados dentro do conjunto de instituições que produziram um artigo. Essa situação pode ser explicada pela possibilidade de um mesmo docente trabalhar em mais de uma instituições de ensino e, consequentemente, não creditar os resultados de suas pesquisas sempre à mesma universidade. Tal situação, por sua vez, acaba gerando impactos negativos nos resultados apresentados pelos indicadores de publicação científica dessas instituições.

A Tabela 4 apresenta os periódicos indexados pela SciELO Brasil com o maior número de publicações sobre docência do Ensino Superior. Como é possível observar, formam o núcleo de representatividade os periódicos: Avaliação: Revista da Avaliação da Educação Superior; Interface - Comunicação, Saúde, Educação; Educar em Revista; Educação e Pesquisa; e Psicologia Escolar e Educacional.

Tabela 4 - Ranking dos periódicos com maior quantidade de publicações sobre docência do Ensino Superior

\begin{tabular}{|c|c|c|}
\hline Ranking & Instituições & Registros \\
\hline \#1 & Avaliação: Revista da Avaliação da Educação Superior & 23 \\
\hline$\# 2$ & Interface - Comunicação, Saúde, Educação & 17 \\
\hline \#3 & Educar em Revista & 15 \\
\hline \#4 & Educação e Pesquisa & 11 \\
\hline \#5 & Psicologia Escolar e Educacional & 10 \\
\hline \#6 & Química Nova & 9 \\
\hline$\# 7$ & Revista Brasileira de Linguística Aplicada & 8 \\
\hline \#8 & Ciência \& Educação & 7 \\
\hline \#9 & Ciência \& Saúde Coletiva & 7 \\
\hline$\# 10$ & Educação em Revista & 7 \\
\hline$\# 11$ & Revista Latino-Americana de Enfermagem & 7 \\
\hline$\# 12$ & Ensaio Pesquisa em Educação em Ciências & 6 \\
\hline$\# 13$ & Ensaio: Avaliação e Políticas Públicas em Educação & 6 \\
\hline$\# 14$ & Revista Brasileira de Educação & 6 \\
\hline$\# 15$ & Revista Brasileira de Educação Médica & 6 \\
\hline \multirow[t]{4}{*}{$\# 16$} & Revista CEFAC & 6 \\
\hline & Periódicos com 3 a 5 artigos publicados & 20 per. \\
\hline & Periódicos com 1 a 2 artigos publicado & 55 per. \\
\hline & Total & 91 per. \\
\hline
\end{tabular}

Fonte: Elaboração própria, a partir de dados coletados do SciELO Citation Index

Nota: Registros refere-se ao número de artigos publicados. 
Depreende-se da Tabela 4 que alguns dos periódicos com mais publicações sobre a docência do Ensino Superior não são específicos da área da Educação, mas de outros campos científicos como da Química, Medicina e Enfermagem. Essa situação pode ser explicada pelo fato da temática docente ser interdisciplinar e, portanto, não se restringir a um único campo do saber. Além disso, conforme a Figura 3, que mostra o mapa conceitual com as palavras-chave mais frequentes utilizadas pelos autores, um dos clusters formados refere-se justamente ao tema saúde (cor verde), incluindo vocábulos como qualidade de vida e distúrbios vocais.

Figura 3 - Clusters formados com os termos mais frequentes extraídos dos periódicos

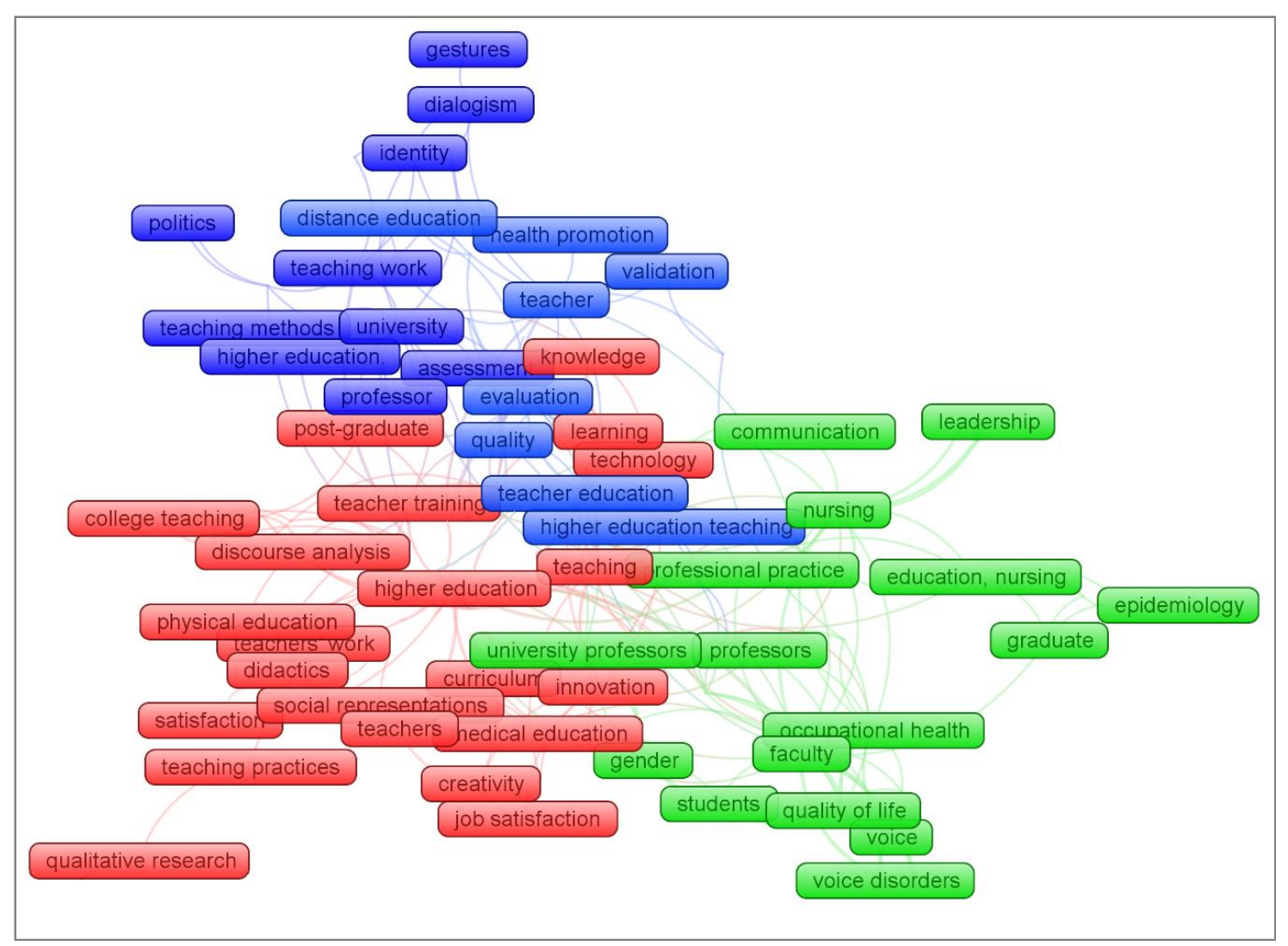

Fonte: Elaboração própria, a partir de dados coletados do SciELO Citation Index

Além do tema saúde, outros dois clusters formaram-se em torno das temáticas avaliação (cor azul) e práticas didáticas (cor vermelha). Cabe ressaltar que as palavras aparecem em inglês, pois o mapa da Figura 3 foi construído com o auxílio do software VOSviewer (versão 1.6.5), que faz a extração apenas das key-words (palavras-chave em inglês) dos artigos. 
De maneira breve, explana-se que o tema avaliação relaciona-se à avaliação das instituições de ensino, dos programas de graduação e pós-graduação, do docente, do aluno, da performance em uma aula, de metodologias avaliativas, da evolução do processo de aprendizagem. O tema das práticas didáticas associa-se às competências acadêmicas, pedagógicas e didáticas, à metodologia e às teorias da prática de ensino-aprendizagem, ao comportamento dentro da sala de aula, às suas habilidades cognitivas e de comunicação, às suas competências para formação de outros profissionais, à inovação da prática docente, à humanização do ensino, aos possíveis estilos adotados ao ministrar uma aula, à prática pedagógica, à preparação das aulas e às tendências didáticas. Por fim, detalhando um pouco mais o tema saúde, este concerne à saúde do docente, ao stress no ambiente de trabalho, aos problemas vocais, à violência dentro da sala de aula, à qualidade de vida, à assistência médica fornecida pelas instituições de ensino, à Síndrome de Burnout e aos fatores de risco associados.

Outro dado fornecido pela SciELO Citation Index diz respeito ao total de citações que cada uma das publicações recebeu até o momento da coleta dos dados. Conforme explicam Lima, Velho e Faria (2012), esta é uma informação que permite avaliar o comportamento da comunidade científica através do reconhecimento que esta oferece aos autores citados. Mueller (2006) complementa que uma maior notabilidade do pesquisador reflete em uma maior visibilidade do periódico no qual a publicação aconteceu. Ou seja, prestigiam-se e são oferecidas maiores recompensas àqueles artigos que alcançaram maiores quantidades de citações. Nesse sentido, a Tabela 5 expõe os títulos das publicações que tiveram mais citações dentro da Rede SciELO, a partir do conjunto de dados analisados, com a indicação dos autores e do periódico em que cada trabalho foi publicado. 
Tabela 5 - Publicações mais citadas na Rede SciELO

\begin{tabular}{|c|c|c|c|}
\hline Autores & Título & Referência & Citações \\
\hline $\begin{array}{l}\text { Nilce Maria da Silva } \\
\text { Campos Costa }\end{array}$ & $\begin{array}{l}\text { Docência no ensino médico: por que } \\
\text { é tão difícil mudar? }\end{array}$ & $\begin{array}{l}\text { Rev. Bras. de Educação } \\
\text { Médica, v. 31, n. 1, } 2007\end{array}$ & 40 \\
\hline $\begin{array}{l}\text { Nilce Maria da Silva } \\
\text { Campos Costa }\end{array}$ & $\begin{array}{l}\text { Formação pedagógica de professores } \\
\text { de nutrição: uma omissão consentida? }\end{array}$ & $\begin{array}{l}\text { Revista de Nutrição, } \\
\text { v. } 22 \text {, n. 1, } 2009\end{array}$ & 13 \\
\hline $\begin{array}{c}\text { Menga Lüdke; } \\
\text { Giseli Barreto da Cruz }\end{array}$ & $\begin{array}{l}\text { Aproximando universidade e escola } \\
\text { de educação básica pela pesquisa }\end{array}$ & $\begin{array}{l}\text { Cadernos de Pesquisa, } \\
\text { v. } 35, \text { n. } 125,2005\end{array}$ & 13 \\
\hline $\begin{array}{l}\text { Luciane Gabeira Secco; } \\
\text { Maria Lúcia T. Pereira }\end{array}$ & $\begin{array}{c}\text { Formadores em odontologia: } \\
\text { profissionalização docente e desafios } \\
\text { político-estruturais }\end{array}$ & $\begin{array}{c}\text { Ciência \& Saúde } \\
\text { Coletiva, v. 9, n.1, } 2004\end{array}$ & 13 \\
\hline $\begin{array}{l}\text { Eunice M. L. S. de } \\
\text { Alencar; } \\
\text { Denise de Souza Fleith }\end{array}$ & $\begin{array}{l}\text { Barreiras à criatividade pessoal entre } \\
\text { professores de distintos níveis de } \\
\text { ensino }\end{array}$ & $\begin{array}{l}\text { Psicologia: Reflexão e } \\
\text { Crítica, v. 16, n.1, } 2003\end{array}$ & 13 \\
\hline $\begin{array}{l}\text { Bárbara N. G. de Goulart; } \\
\text { Brasilia Maria Chiari }\end{array}$ & $\begin{array}{l}\text { Humanização das práticas do } \\
\text { profissional de saúde: contribuições } \\
\text { para reflexão }\end{array}$ & $\begin{array}{c}\text { Ciência \& Saúde } \\
\text { Coletiva, v. 15, n.1, } 2010\end{array}$ & 12 \\
\hline $\begin{array}{l}\text { Vânia Marli S. Backes; } \\
\text { Jose Luis Medina Moyá; } \\
\text { Marta Lenise do Prado }\end{array}$ & $\begin{array}{l}\text { Processo de construção do } \\
\text { conhecimento pedagógico do docente } \\
\text { universitário de enfermagem }\end{array}$ & $\begin{array}{l}\text { Rev. Latino-Amer. de } \\
\text { Enfermagem, v. 19, n. } 2 \text {, } \\
2011\end{array}$ & 11 \\
\hline $\begin{array}{l}\text { Agnaldo Arroio; } \\
\text { Ubirajara P. R. Filho; } \\
\text { Albérico B. F. da Silva }\end{array}$ & $\begin{array}{c}\text { A formação do pós-graduando em } \\
\text { química para a docência em nível } \\
\text { superior }\end{array}$ & $\begin{array}{l}\text { Química Nova, } \\
\text { v. 29, n 6, } 2006\end{array}$ & 11 \\
\hline $\begin{array}{l}\text { Gladys Santos Falcón; } \\
\text { Alacoque L. Erdmann; } \\
\text { Betina H. S. Meirelles }\end{array}$ & $\begin{array}{l}\text { A complexidade na educação dos } \\
\text { profissionais para o cuidado em } \\
\text { saúde }\end{array}$ & $\begin{array}{l}\text { Texto \& Contexto - } \\
\text { Enfermagem, v. } 15, \text { n. } 2 \\
2006\end{array}$ & 11 \\
\hline Maria Eugênia Castanho & $\begin{array}{c}\text { Professores de Ensino Superior da } \\
\text { área da Saúde e sua prática } \\
\text { pedagógica }\end{array}$ & $\begin{array}{l}\text { Interface-Comunicação, } \\
\text { Saúde, Educação, v. 6, n. } \\
\text { 10, } 2002\end{array}$ & 11 \\
\hline
\end{tabular}

Fonte: Elaboração própria, a partir de dados coletados do SciELO Citation Index

De modo similar ao que foi verificado na Tabela 4, é possível observar, pela Tabela 5, que os periódicos dos artigos com os maiores números de citação sobre a docência do Ensino Superior não são específicos da área da Educação, mas de outros campos científicos. Além da temática interdisciplinar, essa situação pode se justificar pela própria característica dos pesquisadores das áreas de Humanidades e Ciências Sociais, que tem uma maior propensão ao uso de referências extraídas de livros e periódicos. Sobre este ponto, Mueller (2005) explica que cada pesquisador tem preferência por um diferente meio de comunicação para publicação dos resultados de suas pesquisas. Assim, a autora mostra que, por exemplo, os autores das áreas das Ciências Exatas e Biológicas preferem publicar em periódicos estrangeiros e aqueles das áreas das Ciências da Saúde em periódicos nacionais. Ademais, pesquisadores das áreas 
das Engenharias têm predileção pela publicação nos congressos científicos, ao passo que os cientistas das áreas das Ciências Humanas e de Linguística, Letras e Artes, preferem as publicações em periódicos nacionais, livros e capítulos de livros. Logo, em cada um dos grandes campos do conhecimento, os pesquisadores divergem quanto ao canal mais apropriado à divulgação científica e busca de informações. Para Gläser e Laudel (2007), este é exatamente um dos motivos pelos quais é necessário ter cuidado ao utilizar da análise de citações para comparação entre diferentes campos científicos.

\section{Conclusão}

Conforme indica a legislação brasileira, o objetivo da Educação Superior é estimular a pesquisa científica, incentivar os meios para criação e divulgação da cultura e incentivar e promover o desenvolvimento dos alunos no que diz respeito aos seus conhecimentos e suas atuações enquanto futuros profissionais. Assim, espera-se que o ensino vá além da simples transferência de conteúdo e que o aluno tenha participação mais ativa no processo de aprendizagem, contribuindo para a construção do seu conhecimento. Verifica-se, entretanto, que, apesar dessa indicação, o modelo tradicional de ensino, pelo qual o professor é o detentor do conhecimento e suas aulas são majoritariamente expositivas, ainda é muito utilizado por vários docentes.

O objetivo deste artigo foi analisar a produção científica acerca da docência no Ensino Superior, haja vista que este ainda é um campo de estudo pouco estudado pela comunidade acadêmica. Dessa forma, tem-se a expectativa de contribuir para a ampliação do acesso a essa informação e orientar as futuras pesquisas a respeito desta temática. Para cumprir este propósito, foram construídos indicadores bibliométricos, elaborados a partir da coleta de dados na base da SciELO Brasil, através do SciELO Citation Index, da Clarivate Analytics Web of Science.

Os resultados apontaram para uma tendência ascendente no número de publicações versando sobre o tema analisado, o que demonstra a importância crescente da discussão dentro da comunidade cientifica. Verificou-se que alguns dos periódicos que mais publicaram artigos sobre o assunto não são específicos da área da Educação, mas de outros campos científicos como Química, Medicina e Enfermagem. Ligado a este ponto, tem-se que as principais temáticas dessa produção foram a respeito das práticas didáticas, sistemas de avaliação e saúde do docente. 
Infere-se, portanto, que há uma grande preocupação da comunidade científica em relação à formação didática do futuro docente do Ensino Superior, fator que têm sido preterido pelos tomadores de decisão ao longo dos anos. Além disso, um tema bastante pesquisado foi em relação à saúde do docente, o que demonstra a importância do cuidado que o professor deve ter durante a realização das suas atividades diárias em sala de aula, mais especificamente no que concerne ao desgaste físico e ao stress e estafa mental, fatores intrínsecos à pratica do ensino nas instituições da Educação Superior.

\section{Referências}

ARAÚJO, Carlos Alberto Ávila. Bibliometria: evolução histórica e questões atuais. Em Questão, Porto Alegre, v. 12, n. 1, p. 11-32, 2006.

BRASIL. Lei n. ${ }^{\circ} 9.394$ de 20 de dezembro de 1996. Estabelece as diretrizes e bases da educação nacional. Diário Oficial - República Federativa do Brasil, Brasília 23 dez. 1996. Disponível em: 〈http://portal.mec.gov.br/arquivos/pdf/ldb.pdf>. Acesso em: 10 jul. 2017.

FERENC, Alvanize Valente Fernandes; MIZUKAMI, Maria da Graça Nicoletti. Formação de professores, docência universitária e o aprender a aprender. In: CONGRESSO ESTADUAL PAULISTA SOBRE FORMAÇÃO DE EDUCADORES, 8., Águas de Lindóia, 2005. Anais... Águas de Lindóia: UNESP, 2005.

FURLANETTO, Ecleide Cunico. Como nasce um professor? Uma reflexão sobre o processo de individuação e formação. São Paulo: Paulus, 2003.

GIL, Antonio Carlos. Didática do ensino superior. São Paulo: Atlas, 2010.

GLÄSER, Jochen; LAUDEL, Grit. The social construction of bibliometric evaluation. In: WHITLEY, R.; GLÄSER, J. The changing governance of the sciences: the advent of research evaluation systems. Dordrecht: Springer, 2007. p.101-126.

HAYASHI, Carlos Roberto Massao. Presença da educação brasileira na base de dados Francis: uma abordagem bibliométrica. 2004. Dissertação (Mestrado em Educação) Universidade Federal de São Carlos, São Carlos, 2004.

LIMA, Ricardo Arcanjo de; VELHO, Lea Maria Leme Strini; FARIA, Leandro Innocentini Lopes de. Bibliometria e "avaliação" da atividade científica: um estudo sobre o índice h.

Perspectivas em Ciência da Informação, Belo Horizonte, v. 17, n. 3, p. 3-17, jul./set. 2012.

MOREIRA, Maria Lígia; VELHO, Lea Maria Leme Strini. Pós-graduação no Brasil: da concepção "ofertista linear" para "novos modos de produção do conhecimento" implicações para avaliação. Avaliação, Campinas, Sorocaba; v. 13, n. 3, p. 625-645, nov. 2008.

Disponível em: < http://www.scielo.br/scielo.php?script=sci_arttext\&pid=S1414$40772008000300002 \& \operatorname{lng}=$ pt\&nrm=iso\&tlng=pt>. Acesso em: 10 jul. 2017.

MUELLER, Suzana Pinheiro Machado. A publicação da ciência: áreas científicas e seus canais preferenciais. DataGramaZero - Revista de Ciência da Informação, Rio de Janeiro, v. 6 , n. 1 , fev. 2005. 
MUELLER, Suzana Pinheiro Machado. A comunicação científica e o movimento de acesso livre ao conhecimento. Ciência da Informação, Brasília, v. 35, n. 2, p. 27-38, maio/ago. 2006.

MUGNAINI, Rogério; DIGIAMPIETRI, Luciano Antonio; MENA-CHALCO, Jesús Pascual. Comunicação científica no Brasil (1998-2012): indexação, crescimento, fluxo e dispersão. TransInformação, Campinas, v. 26, n. 3, p. 239-252, set./dez. 2014.

PACKER, Abel Laerte; MENEGHINI, Rogério. O SciELO aos 15 anos: raison d'être, avanços e desafios para o futuro. In: PACKER, Abel Laerte et al. (Orgs.). SciELO - 15 anos de acesso aberto: um estudo analítico sobre acesso aberto e comunicação científica. Paris: UNESCO, 2014.

PIZZANI, Luciana. O estado da arte da produção científica em educação especial na Biblioteca Virtual em Saúde (BVS): um estudo bibliométrico. 2009. Dissertação (Mestrado em Educação Especial) - Universidade Federal de São Carlos, São Carlos, 2009.

PONCE, Branca Jurema; OLIVEIRA, Juliana Ferrari de. A docência universitária e as políticas públicas de formação: o caso dos cursos de Direito no Brasil. Revista Eletrônica Pesquiseduca, Santos, v. 3, n. 6, p. 200-219, jul./dez. 2011.

ROWE, Diva Ester Okazaki; BASTOS, Antonio Virgílio Bittencourt; PINHO, Ana Paula Moreno. Múltiplos comprometimentos com o trabalho e suas influências no desempenho: um estudo entre professores do ensinos superior no Brasil. Organizações \& Sociedade, Salvador, v. 20, n. 66, jul./set. 2013.

SACARDO, Michele Silva. Estudo bibliométrico e epistemológico da produção científica em Educação Física na Região Centro-Oeste do Brasil. 2012. Tese (Doutorado em Educação) - Universidade Federal de São Carlos, São Carlos, 2012.

SILVA, Rosemary Cristina da. Indicadores bibliométricos da produção científica em Educação Especial: estudo da Revista Educação Especial (2000-2006). 2008. 118p. Dissertação (Mestrado em Educação Especial) - Universidade Federal de São Carlos, São Carlos, 2008.

SOARES, Sandra Regina; CUNHA, Maria Isabel da. Formação do professor: a docência universitária em busca de legitimidade. Salvador: EDUFBA, 2010.

URBIZAGASTEGUI, Ruben. A produtividade dos autores sobre a Lei de Lotka. Ciência da Informação, Brasília, v. 37, n. 2, p. 87-102, maio/ago. 2008.

VANTI, Nadia Aurora Peres. Da bibliometria à webometria: uma exploração conceitual dos mecanismos utiliados para medir o registro da informação e a difusão do conhecimento.

Ciência da Informação, Brasília, v. 31, n. 2, p. 152-162, maio/ago. 2002. 